\title{
In vitro degradation of wheat gluten fractions by Fusarium graminearum proteases
}

\author{
Kai Eggert $\cdot$ Hashadrai M. Rawel $\cdot$ Elke Pawelzik
}

Received: 11 November 2010/Revised: 31 July 2011/ Accepted: 7 August 2011 / Published online: 27 August 2011

(C) The Author(s) 2011. This article is published with open access at Springerlink.com

\begin{abstract}
Fusarium spp. infection of cereal grain is a common problem, which leads to a dramatic loss of grain quality. The aim of the present study was to investigate the effect of Fusarium infection on the wheat storage protein gluten and its fractions, the gliadins and glutenins, in an in vitro model system. Gluten proteins were digested by F. graminearum proteases for 2, 4, 8 and 24 h, separated by Osborne fractionation and characterised by chromatographic (RP-HPLC) and electrophoretic analysis (SDSPage). Gluten digestion by $F$. graminearum proteases showed in comparison with gliadins a preference for the glutenins whereas the HMW subfraction was at most affected. In comparison with a untreated control, the HMW subfraction was degraded of about $97 \%$ after $4 \mathrm{~h}$ incubation with Fusarium proteases. Separate digestion of gliadin and glutenin underlined the preference for HMW-GS. Analogue to the observed change in the gluten composition, the yield of the proteins extracted changed. A higher amount of glutenin fragments was found in the gliadin extraction solution after digestion and could mask a gliadin destruction at the same time. This observation can contribute to explain the frequently reported reduced glutenin amount parallel to an increase in gliadin quantity after Fusarium infection in grains.
\end{abstract}

\footnotetext{
K. Eggert $(\bowtie) \cdot$ E. Pawelzik

Section Quality of Plant Products, Department of Crop Sciences, Faculty of Agricultural Sciences, Georg-August University, 37075 Göttingen, Germany

e-mail: keggert@gwdg.de

H. M. Rawel

Department of Food Chemistry, Institute of Nutritional Science, University of Potsdam, 14558 Nuthetal, Germany
}

Keywords Gluten · Gliadin and glutenin fractions · Peptides $\cdot$ Serine and trypsin protease

\begin{tabular}{ll}
\multicolumn{2}{l}{ Abbreviations } \\
FHB & Fusarium head blight \\
DON & Deoxynivalenol \\
HMW-GS & High molecular weight glutenin subunits \\
LMW-GS & Low molecular weight glutenin subunits \\
NIV & Nivalenol \\
RP-HPLC & $\begin{array}{l}\text { Reverse-phase high-pressure liquid } \\
\text { chromatography }\end{array}$ \\
SDS-Page & Sodium dodecyl sulphate \\
rpm & Revolutions per minute \\
TCA & Trichloric acid \\
TDI & $\begin{array}{l}\text { Tolerable daily intake } \\
\text { Tris }\end{array}$ \\
Tris(hydroxymethyl)-aminomethane \\
Trifluoric acid
\end{tabular}

\section{Introduction}

Fusarium graminearum (teleomorph: Gibberella zeae) is the most relevant Fusarium species in Europe causing Fusarium head blight (FHB) in wheat and barley [1, 2]. Besides $F$. graminearum and $F$. culmorum, a number of other Fusarium spp. are also known to cause FHB [1, 3]. Fusarium graminearum produces trichothecene mycotoxins such as nivalenol (NIV) and deoxynivalenol (DON) [4]. High concentrations of Fusarium toxins in the diet lead to adverse effects on human and animal health. Typical symptoms are vomiting, diarrhoea, internal bleeding of the intestines at high doses with an impairment of the immune function and the inhibition of protein synthesis [5-7]. These toxic effects make the reduction of trichothecene 
content in food and feed essential; therefore, the European Union has limited the maximum concentrations of DON tolerated in products destined for human food (TDI: $1 \mu \mathrm{g}$ DON $\mathrm{kg}^{-1}$ bodyweight/day; maximum concentration in unprocessed crop: $1,250 \mu \mathrm{g} \mathrm{kg}^{-1}$ ) [Commission Regulation (EC) No. 856/2005. 2006] and for animal nutrition (crop and crop products: $8,000 \mu \mathrm{g} \mathrm{kg}^{-1}$ at $12 \%$ moisture content) [Commission Regulation (EC) No. 576/2006. 2006].

The viscoelastic properties of the storage protein fractions (gluten) in wheat are essential for the use and the processing quality of bread and bakery products [8]. Gluten-forming proteins absorb water and form a network during dough making which is able to retain gas during the baking process and results in an elastic crumb structure $[9,10]$. For analyses of gluten proteins, the classical extraction procedure is the one described by Osborne [11]. The stepwise separation of the proteins in salty water, alcohol and buffer solution under reducing conditions results in an albumin/globulin fraction, a gliadin fraction and glutenin fraction, respectively, which differ in their functional contribution during wheat processing. Wieser et al. [12] established the separation of gliadins and glutenins into subfractions (gliadins: $\omega-, \alpha$ - and $\gamma$-gliadins; glutenins: $\omega$-glutenin, high molecular weight glutenin (HMW-GS) and low molecular weight glutenin (LMW-GS) by RP-HPLC.

Fusarium infection and the consequent production of proteases by the fungus lead to gluten degradation, thus changing dough consistence and resistance to extension, which results in a loss of dough functionality and loaf volume [9]. Recent studies focusing on the influence of Fusarium infection on grain proteins have documented either no or just a moderate impact on total protein content and supposed a dependence of protein degradation on the degree of infection with Fusarium spp. [13, 14]. However, an influence on the proportion and composition of the protein fractions such as an increase in gliadin and a reduction in glutenin content has also been observed [14, 15]. Fungal proteases produced by Fusarium spp. include trypsin-, serine- or subtilisin-like proteases as well as protein phosphatases, serine peptidases, aminopeptidases and alkaline proteinases. They are part of the exoproteome of the fungus and degrade proteins in both wheat and barley grains [16-18]. Fusarium proteases are mainly reported to be trypsin-like serine proteases that cut the proteins at the lysine or arginine amino acid [16, 19]. A study that investigated the ability of Fusarium proteases from $F$. graminearum, $F$. avenaceum and $F$. poae to degrade gliadin in an in vitro trail observed a degradation of gliadin just after $F$. poae treatment but not after $F$. graminearum treatment [20]. An earlier study explained the reduction of the glutenin fractions and the increase in the quantity of the gliadin fraction after Fusarium infection with the differing impact of the fungus on protein synthesis during maturation stages [14]. However, a further study did not show any alterations in the protein synthesis behaviour during grain maturation and only a belated polymerisation of glutenins was observed [21]. Therefore, the true nature of protein alteration by Fusarium spp. is still a matter of discussion.

The present study contributes to a better understanding of the degradation of storage proteins by Fusarium spp. An in vitro experiment was performed in which the effect of proteases produced by $F$. graminearum, the main causal agent of Fusarium head blight in small cereal grain, on gluten-forming proteins was investigated. It was of interest if Fusarium proteases prefer the degradation of particular subfractions of gluten. Therefore, the separate digestion of gliadin and glutenin by fungal proteases was initiated. The quantification and characterisation of the liberated products were performed by RP-HPLC and SDS-Page. The present study can contribute to the fundamental understanding of protein degradation observed in earlier studies resulting from Fusarium infection and the potential of protease action during wheat flour processing [13-15].

\section{Materials and methods}

\section{Protein extraction procedure}

The extraction procedure was adapted with modifications from the method of Wieser et al. [12]. Commercially available gluten from wheat (Sigma-Aldrich Chemie $\mathrm{GmbH}$, Steinheim, Germany) was used for extraction of gliadin and glutenin. The crude gluten was washed twice with a fivefold quantity of an albumin and globulin-

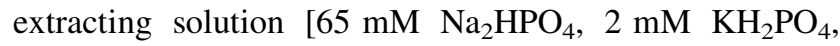
with $400 \mathrm{mM} \mathrm{NaCl}, \mathrm{pH} \mathrm{7.6]} \mathrm{for} 30 \mathrm{~min}$ to remove any leftover of albumin and globulin. In each extraction cycle, the sample was centrifuged for $20 \mathrm{~min}$ at $1,700 \mathrm{~g}$ and the supernatant was discarded. The salt was removed by washing the pellet for $30 \mathrm{~min}$ with distilled water and centrifuged for $20 \mathrm{~min}$ at $1,700 \mathrm{~g}$ and the supernatant was discarded again. All of the steps were performed at room temperature $\left(25^{\circ} \mathrm{C}\right)$.

Gliadin was extracted from the gluten as described above. The gluten pellet was suspended for three times with a fivefold quantity of the extraction solution containing $60 \%$ ethanol $(\mathrm{v} / \mathrm{v})$ by homogenisation of the pellet for $1 \mathrm{~min}$ at 24,000 rpm with an ultra turrax $\left(\mathrm{IKA}^{\circledR}\right.$ Werke GmbH \& Co. KG, Staufen, Germany). The suspension was shaken vigorously for $30 \mathrm{~min}$ and centrifuged at $1,700 \mathrm{~g}$ for $20 \mathrm{~min}$ at room temperature. The gliadin-containing supernatants were combined and filtered (MN 616 $1 / 4$ 150 mm; MACHERY-NAGEL GmbH \& Co. KG, Düren, 
Fig. 1 Model system for the isolation of $F$. graminearum protease extract and degradation of wheat gluten and gluten fractions. Wheat grains were milled, mixed with water and autoclaved. Fusarium graminearum (FG 142, 143, 144) macro conidiospores $\left(0.5 \times 10^{6} \mathrm{ml}^{-1}\right)$ were added to sterile medium and incubated for 30 days at $20^{\circ} \mathrm{C}$. Fusarium proteases were extracted with Tris- $\mathrm{HCl}$ and used for incubation and degradation of the total gluten as well as gliadin and glutenin separately over different time periods. Proteins and peptides were isolated and detected by RP-HPLC and SDS-Page
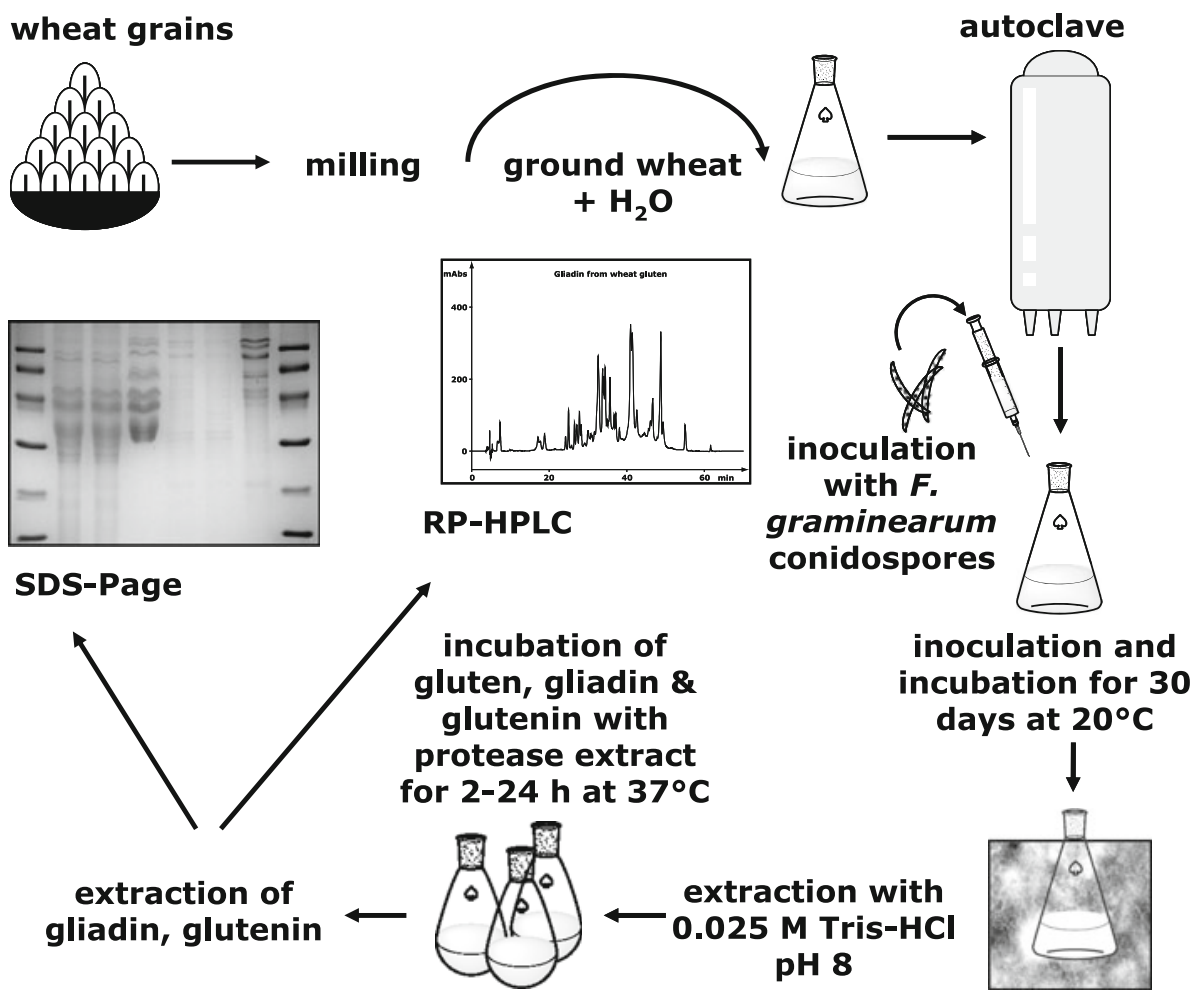

Germany). The ethanol was evaporated at $40{ }^{\circ} \mathrm{C}$ for $24 \mathrm{~h}$ from the gliadin and the residue was freeze-dried (CHRIST Gefriertrocknungsanlagen, EPSILON 2-40, Osterode, Germany), homogenised by pestle under liquid nitrogen $\left(\mathrm{N}_{2}\right)$ and stored at $-20{ }^{\circ} \mathrm{C}$.

Glutenin was extracted twice with a fivefold quantity of the extraction solution [containing 50\% 1-propanol (v/v) mixed with $50 \%$ of $2 \mathrm{~mol} / 1$ urea, $0.05 \mathrm{~mol} / \mathrm{l}$ Tris/ $\mathrm{HCl}(\mathrm{pH}$ 7.5) and $1 \%$ dithioerythritol] by homogenisation of the pellet for $1 \mathrm{~min}$ at $24,000 \mathrm{rpm}$ with an ultra turrax. The suspension was shaken vigorously for $30 \mathrm{~min}$ at $60{ }^{\circ} \mathrm{C}$ and centrifuged for $20 \mathrm{~min}$ at 5,214 $\mathrm{g}$ at room temperature. The glutenin-containing supernatants were combined, filtered and dialysed for $24 \mathrm{~h}$ in a cellulose acetate tube against distilled water. The residue was freeze-dried, homogenised by pestle under liquid $\mathrm{N}_{2}$ and washed again three times with $60 \%(\mathrm{v} / \mathrm{v})$ ethanol to remove any gliadin residue. Finally, the pellet was washed with ice-cold $\left(-20^{\circ} \mathrm{C}\right)$ acetone, dried under $\mathrm{N}_{2}$ and stored at $-20{ }^{\circ} \mathrm{C}$.

Preparation of Fusarium graminearum protease solution

Fusarium graminearum isolates (FG 142, 143, 144) were DON-producing strains and were obtained the reference stock of the Division of Plant Pathology and Crop Protection at the Department of Crop Science of the Georg-August-University, Göttingen. Macro conidiospore production was conducted on autoclaved wheat straw suspension which represented a nutrient deficient medium for 7 days at $20{ }^{\circ} \mathrm{C}$ containing $9 \mathrm{~g}$ straw, $300 \mathrm{ml}$ distilled water and $60 \mathrm{mg}$ streptomycin (Carl Roth $\mathrm{GmbH}+\mathrm{Co}$. $\mathrm{KG}$, Karlsruhe, Germany). From each isolate grown on oatmeal agar, five discs were punched out with a cork borer and added to the straw suspension. Macro conidiospores quantification was accomplished using a Fuchs-Rosenthal

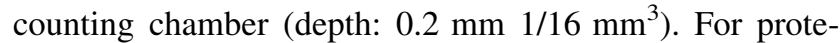
ase production, $1 \mathrm{ml}$ of macro conidiospore suspension $\left(0.5 \times 10^{6} \mathrm{ml}^{-1}\right)$ from each isolate was added to an aseptical medium containing $5 \mathrm{~g}$ of wheat seeds (Triticum aestivum, L.) milled to less than $0.5 \mathrm{~mm}$ particle size (Retsch ZM 100, Haan, Germany) in $30 \mathrm{ml}$ of distilled water in a $250 \mathrm{ml}$ Erlenmeyer flask which was autoclaved twice for $15 \mathrm{~min}$ at $121^{\circ} \mathrm{C}$ (Fig. 1). Each isolate was incubated two times for 30 days at $20^{\circ} \mathrm{C}$ at day/night frequency. After incubation, $F$. graminearum proteases were extracted from the media for $16 \mathrm{~h}$ with $40 \mathrm{ml}$ sterile Tris-HCl buffer (25 mmol, $\mathrm{pH} 8$ [16]) by gentle shaking at $4{ }^{\circ} \mathrm{C}$. Afterwards, the extracts were filtered over a hair sieve, centrifuged for $15 \mathrm{~min}$ at $3,830 \mathrm{~g}$ and combined in equal parts. The extract mixture was used to minimise differences in protease production that depend on the isolate and to ensure an adequate protease production. For control, medium without macro conidia was incubated and extracted under the same conditions. All extracts were stored at $-20{ }^{\circ} \mathrm{C}$ for further analyses (Fig. 1). 
Protein incubation and extraction

Two sets of experiments were performed: (1) Proteolysis of gluten by Fusarium protease, followed by extraction of the gliadins and glutenins and investigation of them by RP-HPLC and SDS-Page. (2) Proteolysis of the isolated and purified gliadins and glutenins by Fusarium protease, and investigation of them by the above-mentioned methods.

\section{Proteolysis}

Each of $20 \mathrm{mg}$ gluten, gliadin and glutenin were weighed in $2 \mathrm{ml}$ reaction tubes. For proteolysis, each of $1 \mathrm{ml}$ of protease extract was added to the tubes. All samples were gentle shaken at $37{ }^{\circ} \mathrm{C}$. For gluten samples, the incubation durations were 4 and $24 \mathrm{~h}$, whereas for gliadin and glutenin samples incubation durations of 2, 4 and $8 \mathrm{~h}$, respectively, were applied (Fig. 1). The proteolysis was stopped by adding $1 \mathrm{ml}$ of ice-cold $\left(-20{ }^{\circ} \mathrm{C}\right)$ acetone with $20 \%$ trichloroacetic acid (TCA) to the reaction mixtures. Thereafter, the solutions were vortexed for $30 \mathrm{~s}$ and the samples were stored for $12 \mathrm{~h}$ at $-20{ }^{\circ} \mathrm{C}$.

\section{Protein extraction after proteolysis}

The samples were centrifuged for $20 \mathrm{~min}$ at $-9{ }^{\circ} \mathrm{C}$ and $20,000 \mathrm{~g}$. The supernatants from the separately incubated gliadin and glutenin fractions were collected and stored at $-20^{\circ} \mathrm{C}$ for further RP-HPLC determination of the peptides. The pellets were washed with ice-cold acetone at $-20^{\circ} \mathrm{C}$ for $30 \mathrm{~min}$, again centrifuged at the same conditions given above. Finally, the pellets were dried under $\mathrm{N}_{2}$. For gliadin extraction, the respective pellet was treated twice with $1 \mathrm{ml}$ of $60 \%$ (v/v) ethanol. Then, the pellet was homogenised with a hand mixer at 7,000 rpm (Xenox S.A. Xenox-Motorised Hand Tool, Wecker, Luxemburg), shaken for $20 \mathrm{~min}$ at $20{ }^{\circ} \mathrm{C}$ and centrifuged for $20 \mathrm{~min}$ at $20^{\circ} \mathrm{C}$ and $20,000 \mathrm{~g}$. The resulting supernatant was divided into two aliquots —one for RP-HPLC and the other for SDS-Page. The gluten and glutenin pellets were extracted twice with the glutenin extraction solution [containing 50\% 1-propanol (v/v) mixed with $50 \%$ of $2 \mathrm{~mol} / 1$ urea, $0.05 \mathrm{~mol} / 1 \mathrm{Tris} / \mathrm{HCl}(\mathrm{pH} 7.5)$ and $1 \%$ dithioerythritol]. The samples were homogenised with a hand mixer at 7,000 rpm (Xenox S.A. Xenox-Motorised Hand Tool, Wecker, Luxemburg), shaken for $30 \mathrm{~min}$ at $60{ }^{\circ} \mathrm{C}$ under $\mathrm{N}_{2}$ and the obtained extracts were centrifuged at 7,000 $\mathrm{g}$ for $20 \mathrm{~min}$ at $20{ }^{\circ} \mathrm{C}$. The supernatants were divided into two aliquots according to the gliadin sample.

\section{Sample preparation for SDS-Page}

To a $1 \mathrm{ml}$ sample solution from the gliadin and glutenin extract, $1 \mathrm{ml}$ ice-cold $\left(-20{ }^{\circ} \mathrm{C}\right)$ acetone with $20 \%$ TCA was added. The samples were stored for $12 \mathrm{~h}$ at $-20{ }^{\circ} \mathrm{C}$. Afterwards, the samples were centrifuged for $20 \mathrm{~min}$ at $-9{ }^{\circ} \mathrm{C}$ and $20,000 \mathrm{~g}$. The obtained pellets were washed with ice-cold acetone and dried under $\mathrm{N}_{2}$.

\section{RP-HPLC}

A dual pump mode Shimadzu 10A system (Duisburg, Germany) with a PerfectSil 300 C8 column $300 \times 4.5 \mathrm{~mm}$, $300 \AA$ А $5 \mu \mathrm{m}$ (MZ-Analysentechnik GmbH, Mainz, Germany) was used. The flow rate was $1 \mathrm{ml} / \mathrm{min}$ and detection was performed at $220 \mathrm{~nm}$ with a column temperature of $50{ }^{\circ} \mathrm{C}$. The two eluents were $\mathrm{A}=0.1 \%$ TFA in distilled water and $\mathrm{B}=$ acetonitrile. The gradient was applied under the following conditions: $100 \%$ eluent A, 0 min; $76 \%$ eluent A, 5 min; $50 \%$ eluent A, 50 min; $10 \%$ eluent A, $51 \mathrm{~min} ; 10 \%$ eluent A, $56 \mathrm{~min} ; 100 \%$ eluent A, 57-70 min (regeneration/equilibration). The injection volumes of the samples were as follows: $100 \mu$ for the peptide fraction, $50 \mu \mathrm{l}$ for the samples from gliadin and glutenin proteolysis and $200 \mu \mathrm{l}$ for the ethanol-soluble glutenins. The content of each of $20 \mathrm{mg}$ of gluten, gliadin and glutenin used for proteolysis was used to quantify the proteins using the AUC (area under the curve).

\section{SDS-Page}

A mini SDS-Page (Bio-Rad Laboratories GmbH, Munich, Germany) was used and the separation according to the method of Laemmli performed [22]. The separation conditions of the gel were for the separating gel $14 \% \mathrm{~T}$ and the stacking gel $10 \% \mathrm{~T}$. The samples were dissolved in a sample buffer with the following composition: $4 \%$ sodium dodecyl sulphate 'SDS', $12 \%$ glycerol, $0.61 \%$ Tris- $\mathrm{HCl}, 5 \%$ mercaptoethanol, $1 \%$ dithioerythritol and $0.01 \%$ Coomassie Brilliant Blue R 250 with $\mathrm{pH}$ 6.8. The protein pellets were dissolved in $1 \mathrm{ml}$ sample buffer for gliadin and glutenin and in $200 \mu \mathrm{l}$ sample buffer for destructed glutenins soluble in $60 \%(\mathrm{v} / \mathrm{v})$ ethanol. The protein solutions were treated for $5 \mathrm{~min}$ in an ultrasonic bath, heated at $90{ }^{\circ} \mathrm{C}$ for $3 \mathrm{~min}$. To each slot, $10 \mu \mathrm{l}$ of the sample solution was applied. A standard of $10 \mu \mathrm{l}$ of calibration proteins (Amersham Bioscience Europe GmbH, Freiburg, Germany) dissolved in $300 \mu$ l sample buffer were added to each gel as molecular weight markers.

\section{Statistical analysis}

Generally, the analyses were repeated at least three times and evaluated by their means and standard deviations. 

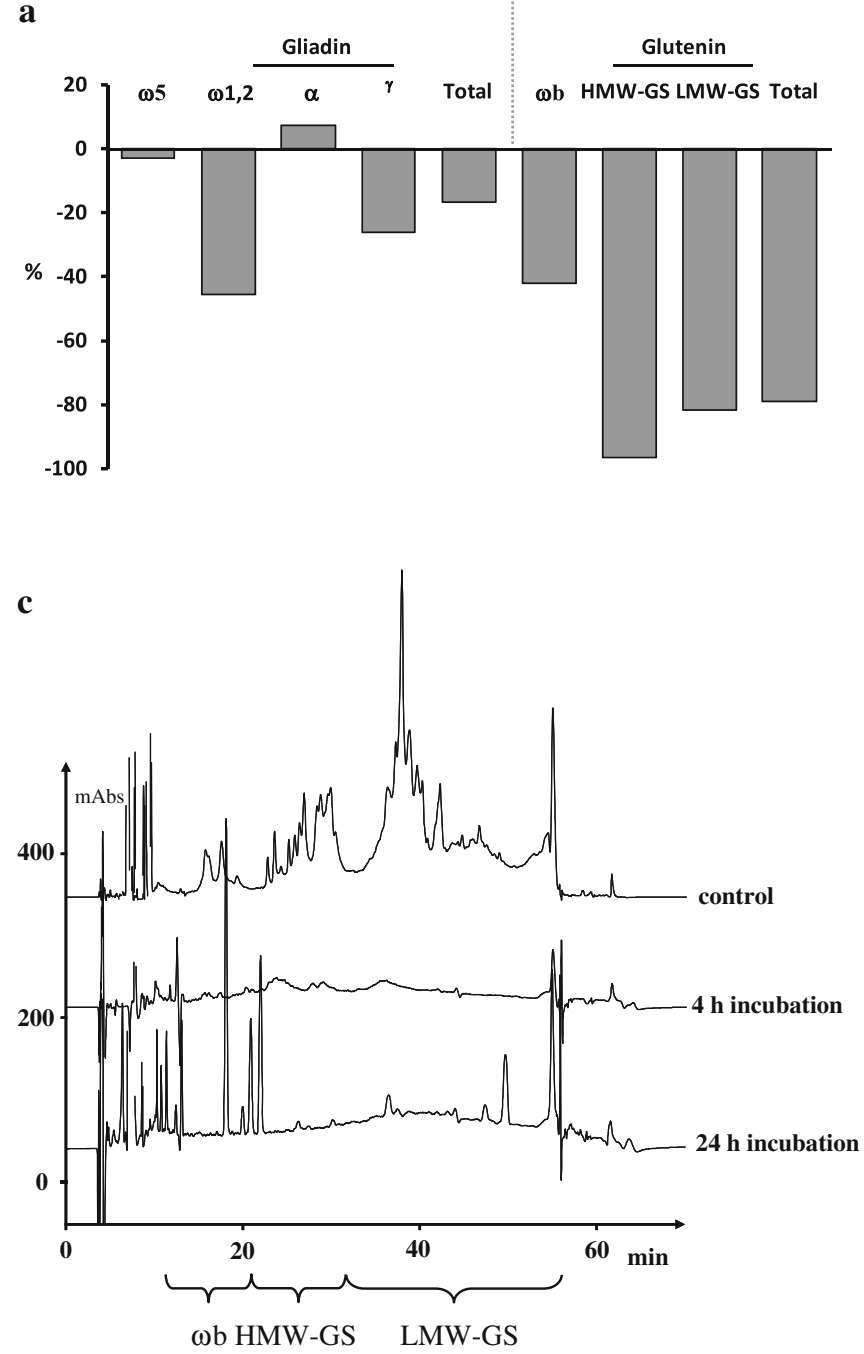

Fig. 2 a Degradation of gliadins and glutenins as well as subfractions extracted from gluten after $4 \mathrm{~h}$ incubation with $F$. graminearum proteases as \% peak area in comparison with control. b RP-HPLC results of degraded wheat gliadin subfractions $(\omega 5-, \omega 1,2-, \alpha-$, $\gamma$-gliadin) extracted from gluten after 4 and $24 \mathrm{~h}$ of incubation with $F$. graminearum proteases in comparison with control, (mAbs, micro absorption units). c RP-HPLC results of degraded wheat glutenin subfractions ( $\omega \mathrm{b}-$, HMW-, LMW-glutenin) extracted from gluten

\section{Results and discussion}

Digestion of wheat gluten by $F$. graminearum protease

An incubation of gluten with Fusarium proteases for $4 \mathrm{~h}$ led to a reduction of about $17 \%$ in gliadins and $80 \%$ in glutenins in comparison with the control (Fig. 2a). After $24 \mathrm{~h}$, the chromatograms showed complete absence of gliadins and the loss of typical glutenins fractions (Fig. 2b, c). A $4 \mathrm{~h}$ incubation with Fusarium proteases led to a stronger degradation of the glutenin fraction compared to the gliadins (Fig. 2a-d), indicating a preferred digestion of

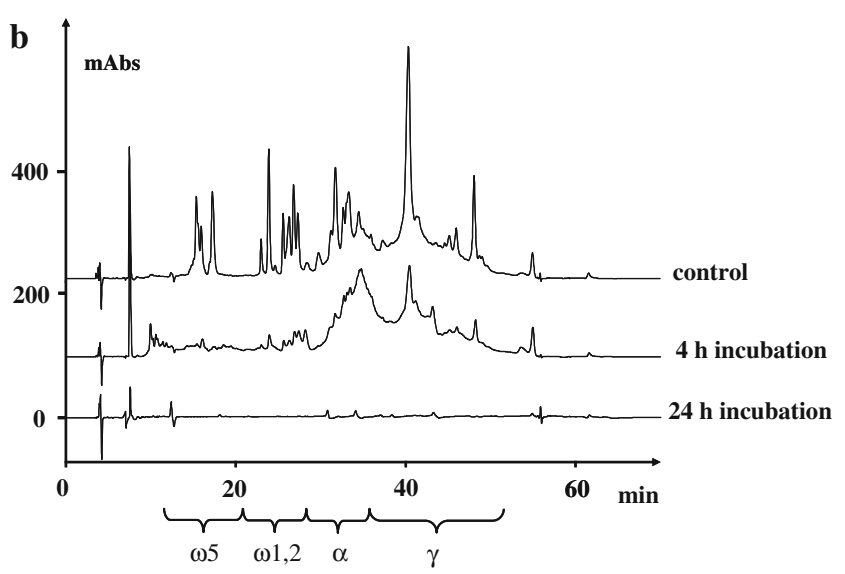

d

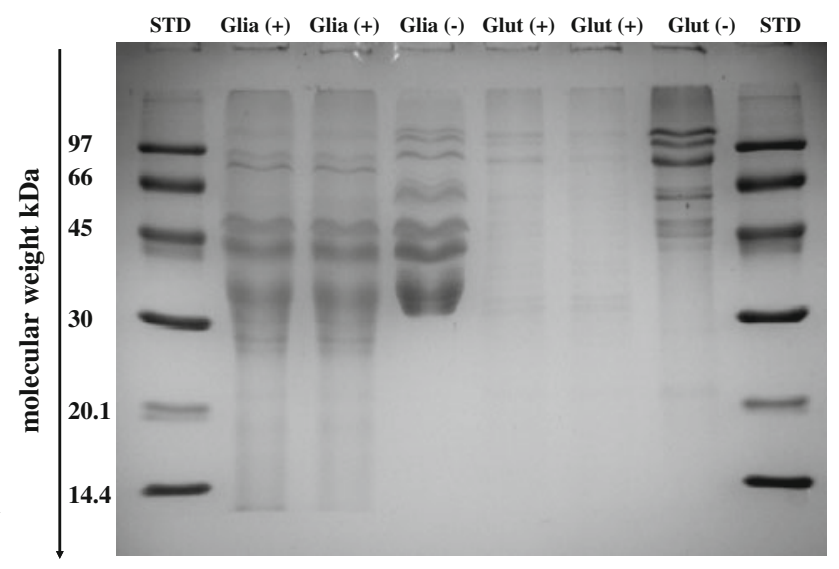

after 4 and $24 \mathrm{~h}$ of incubation with $F$. graminearum proteases in comparison with control, (mAbs, micro absorption units). d Results of SDS-Page showing the degradation of wheat gliadin and glutenin subfractions extracted from gluten after a $4 \mathrm{~h}$ incubation with $F$. graminearum proteases. Key: STD Standard, Glia (+) proteasedegraded gliadin, Glia (-) control gliadin, Glut (+) proteasedegraded glutenin, Glut (-) control glutenin

glutenins by the proteases. The more distinct reduction of glutenins in comparison with gliadins has also been ascertained in naturally and artificially infected samples from field trials $[14,15]$. Contradictory to these results, another study did not find a degradation of gliadin after incubation with $F$. graminearum proteases which may be explained with different in vitro conditions applied [20]. Within the gliadins, the most affected subfractions were $\omega 1.2$-gliadins which were reduced about $45 \%$ and $\gamma$-gliadins which were reduced about $26 \%$ in comparison with the control (Fig. 2c). At the same time, an increase in $\alpha$-gliadin about $7 \%$ could be observed. We assume that the 
differences in the breakdown of the gliadin subfractions may result from a change in solubility of digested gluten fractions which has been discussed in an earlier study [15].

The strongest impact of fungal proteases on glutenin subfractions was observed for HMW-GS (Fig. 2b, c), which decreased about $97 \%$ after $4 \mathrm{~h}$ incubation. LMW-GS decreased about $82 \%$ and $\omega$ b glutenins about $42 \%$. These results underline the high susceptibility of glutenins to the digestion by proteases from $F$. graminearum. These proteases have been reported to be mainly trypsin-like serine proteases that cut the proteins at the lysine or arginine amino acid [16, 19]. A possible explanation for the primary destruction of HMW-GS in comparison with LMW-GS is their relatively higher quantity of lysine or arginine. In literature, lysine contents between 0.7 and $1.4 \%$ for HMWGS and between 0 and $<1 \%$ for LMW-GS were reported, while no difference in arginine content between the two fractions was described [23-25]. Therefore, we assume that lysine is the crucial amino acid responsible for the observed higher breakdown of HMW-GS compared to LMW-GS. HMW-GS are, when compared to other glutenin subfractions, predominantly responsible for the elastic properties of the dough and strongly positively associated to a high baking volume [10]. Therefore, the breakdown of HMW-GS by Fusarium proteases may contribute to explain the observed decrease in dough quality and baking performance after Fusarium infection of wheat [9].

Digestion of purified gliadin and glutenin by $F$. graminearum protease

The incubation of just gliadins with Fusarium proteases resulted in a decrease in total gliadins over 2,4 and $8 \mathrm{~h}$
Table 1 Degradation of gliadin (Fig. 2b) and glutenin (Fig. 3b) subfractions remaining after incubation with $F$. graminearum protease in \% peak area in comparison with control; for abbreviations of the subfractions, see 'Abbreviations'

\begin{tabular}{llccc}
\hline Protein & Subtraction & \multicolumn{3}{l}{ Incubation time (h) } \\
\cline { 3 - 5 } & & 2 & 4 & 8 \\
\hline Gliadin & $\omega 5$ & 88 & 89 & 86 \\
& $\omega 1,2$ & 78 & 91 & 94 \\
& $\alpha$ & 76 & 88 & 94 \\
& $\gamma$ & 75 & 88 & 94 \\
\multirow{5}{*}{ Glutenin } & Total & 77 & 88 & 94 \\
& $\omega b$ & 0 & 0 & 10 \\
& HMW-GS & 39 & 47 & 58 \\
& LMW-GS & 13 & 28 & 43 \\
& Total & 16 & 30 & 45 \\
\hline
\end{tabular}

Table 2 Peptide release from purified gliadin, glutenin and the amounts of degraded glutenins soluble in the gliadin extraction solution after incubation with $F$. graminearum proteases in comparison with control. Results are presented as means $\pm \mathrm{SD}(n=3)$

\begin{tabular}{lrlll}
\hline Protein & Control & \multicolumn{4}{l}{ Incubation time $(\mathrm{h})$} \\
\cline { 3 - 5 } & 0 & \multicolumn{2}{l}{$\begin{array}{l}2 \\
\text { Peak area } \times 10^{-6}\end{array}$} \\
\hline Gliadin & $2.9 \pm 1.8$ & $28.4 \pm 1.7$ & $54.9 \pm 1.3$ & $84.0 \pm 3.9$ \\
Glutenin & $0.7 \pm 0.4$ & $44.4 \pm 0.2$ & $67.4 \pm 10.9$ & $89.2 \pm 2.7$ \\
Glutenins & $45.5 \pm 3.2$ & $66.6 \pm 29.2$ & $71.6 \pm 0.5$ & $74.4 \pm 7.7$ \\
$\quad \begin{array}{l}\text { soluble in } \\
\text { gliadin } \\
\text { fraction }\end{array}$ & & & & \\
\hline
\end{tabular}
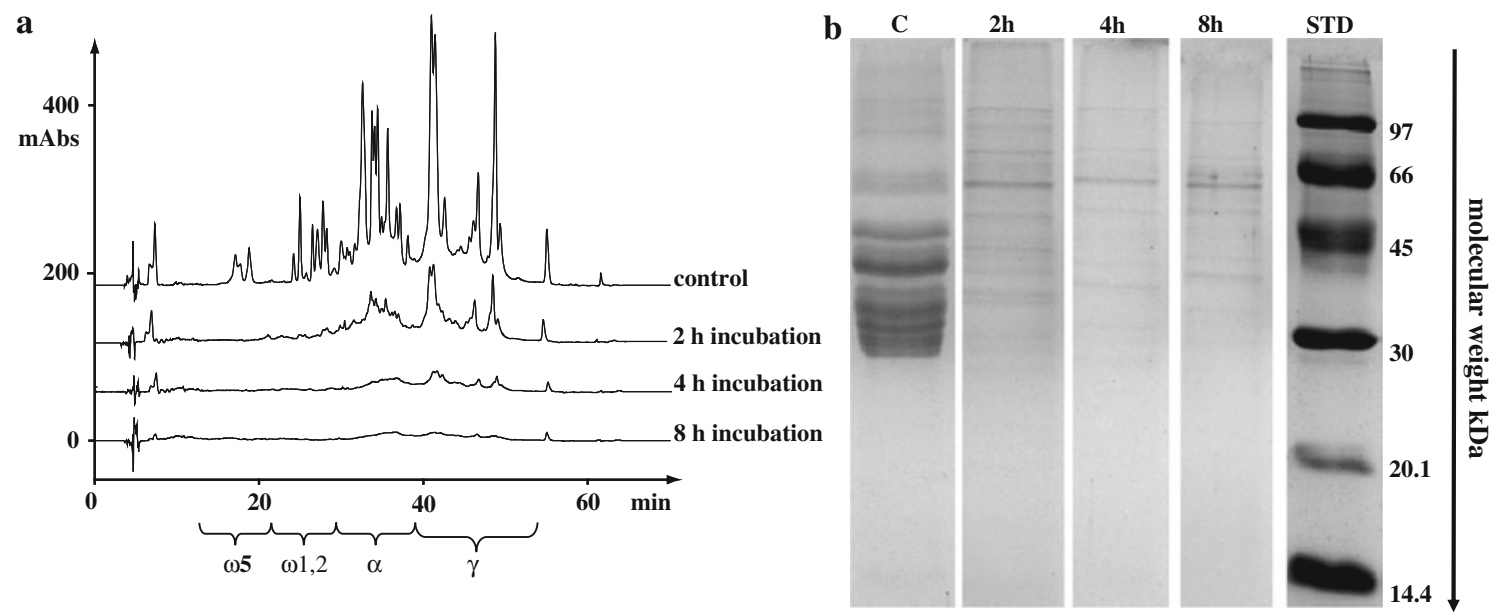

Fig. 3 a RP-HPLC results of degraded gliadin subfractions $(\omega 5-$, $\omega 1,2-, \alpha$-, $\gamma$-gliadins) after incubation with $F$. graminearum proteases in comparison with control, (mAbs, micro absorption units). b SDS-
Page results of gliadin degradation after incubation with $F$. graminearum proteases for 2, 4 and $8 \mathrm{~h}$ (STD standard, $C$ control) 

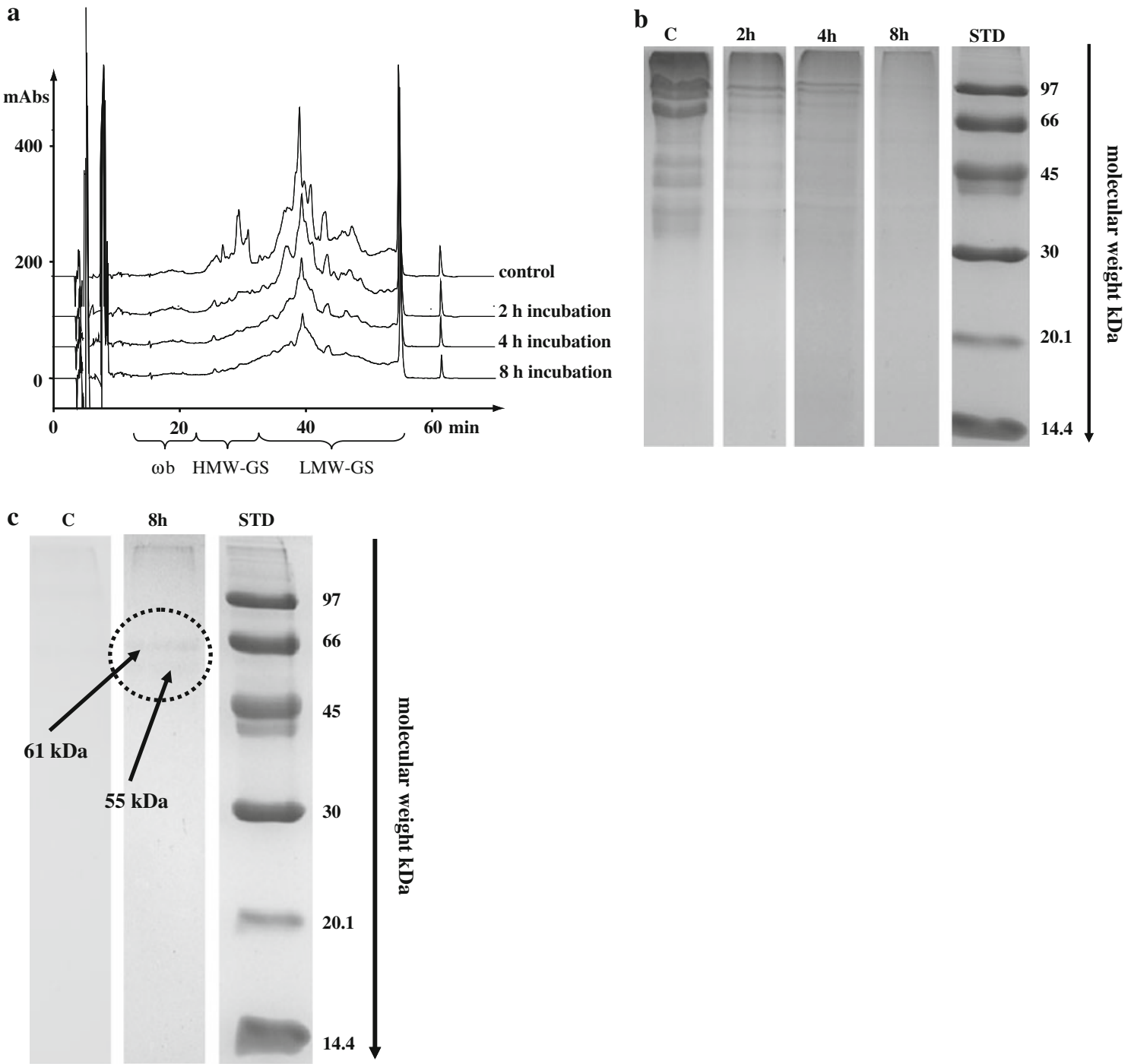

Fig. 4 a RP-HPLC results of degraded glutenin subfractions ( $\omega \mathrm{b}-$, HMW-, LMW-glutenin) after incubation with $F$. graminearum proteases in comparison with control, (mAbs, micro absorption units). b SDS-Page results of glutenin degradation after incubation with $F$. graminearum proteases for 2, 4 and $8 \mathrm{~h}$ (STD standard, $C$ control).

about 77,88 and $94 \%$, respectively. All gliadin subfractions were decreased in a range of $88-91 \%$ (Table 2; Fig. 3a, b). Obviously, if only gliadins acted as substrate for the fungal proteases, a stronger destruction of gliadins took place compared to degradation of total gluten (Table 1; Figs. 2a-c and 3a, b). These results confirm the hypothesis that besides glutenin digestion, gliadin degradation also takes place in infected wheat grains [15]. This can be confirmed by the increasing formation of peptides from gliadin detected after 2, 4 and $8 \mathrm{~h}$ of incubation in comparison with the control (Table 2). The breakdown of gliadins by Fusarium proteases shows the potential of these proteases to degrade all of the gliadin fractions completely c SDS-Page results of glutenins soluble in the gliadin extraction solution containing $60 \%(\mathrm{v} / \mathrm{v})$ ethanol after an $8 \mathrm{~h}$ incubation period with $F$. graminearum proteases in comparison with control (STD standard, $C$ control)

(Figs. 2a, 3a) and documents the eligibility of these enzymes as a prospective degrading tool with regard to coeliac disease [26, 27].

The degradation of purified glutenins occurred to a lower extent when compared to purified gliadins. After 2, 4 and $8 \mathrm{~h}$ incubation with proteases, total glutenin was reduced about 16, 30 and $45 \%$, respectively. Again, HMWGS were affected the most and reduced about $47 \%$ after $4 \mathrm{~h}$ of incubation, whereas LMW-GS decreased about $28 \%$ (Table 1; Fig. 4a, b). Glutenins which were soluble in gliadin extraction solution increased with incubation time (Table 2). The higher solubility of protein fractions resulting from glutenin digestion could additionally be 
confirmed by SDS-PAGE where two fragments with a molecular weight of 61 and $55 \mathrm{kDa}$ after an $8 \mathrm{~h}$ incubation time could be detected (Fig. 4c). These results confirm that fragments resulting from glutenin digestion by fungal proteases are most likely extracted with the gliadin fraction in samples. Because these fractions are co-detected with the gliadin fraction by RP-HPLC, the destruction of gliadins is masked. Higher gliadin content and lower glutenin content after Fusarium infection were described in earlier studies and can now be explained with the masking of gliadin destruction by glutenin fragments $[14,15]$. This aspect has yet not been considered so far in the discussion of altered gliadin and glutenin contents in Fusarium infected wheat samples from field trials [14]. Nevertheless, further experiments are necessary to analyse the degradation of gliadins and glutenins by fungal proteases. Low abundant subfractions could be identified with 2D-Page and MALDI-TOF-MS and provide a better understanding of the consequent allocation of the subfractions of gliadins and/or glutenins. Additionally, it can be an interesting biochemical approach to identify basic mechanisms in interaction between proteases and the substrate, wheat storage proteins, by an in vitro test system with Fusarium proteases. Therefore, the present study is the initial point for further analysis of wheat storage proteins by Fusarium proteases with biochemical methods.

\section{Conclusion}

The present study revealed a preference of $F$. graminearum proteases for the digestion of glutenins rather than gliadins during gluten digestion. Within the glutenin subfractions, the HMW-GS subfraction was the strongest affected one. This effect probably results from the specificity of the Fusarium proteases. The separated digestion of gliadin and glutenin by $F$. graminearum proteases confirmed former results from field samples, i.e. a clear effect on both gliadin and glutenin fractions. The formation of a protein fraction with higher solubility in the gliadin extraction solution after incubation with proteases was also observed. This result indicates that fragments from purified glutenin can be falsely allocated to gliadin subfractions and lead to the conclusion that the amount of gliadins increases over time during incubation with $F$. graminearum proteases. Therefore, the allocation of wheat gluten subfractions according to their solubility in different solvents and their conventional analysis by RP-HPLC may lead to false conclusions, especially if wheat grain had been exposed to Fusarium infection. This underlines the need for application of more advanced methods for characterisation of gliadins and glutenins.
Open Access This article is distributed under the terms of the Creative Commons Attribution Noncommercial License which permits any noncommercial use, distribution, and reproduction in any medium, provided the original author(s) and source are credited.

\section{References}

1. Parry DW, Jenkinson P, McLeod L (1995) Fusarium ear blight (scab) in small-grain cereals-a review. Plant Pathol 44:207-238

2. Foroud NA, Eudes F (2009) Trichothecenes in cereal grains. Int J Mol Sci 10:147-173

3. Yazar S, Omurtag GZ (2008) Fumonisins, trichothecenes and zearalenone in cereals. Int J Mol Sci 9:2062-2090

4. Bottalico A, Perrone G (2002) Toxigenic Fusarium species and mycotoxins associated with head blight in small-grain cereals in Europe. Eur J Plant Pathol 108:611-624

5. Eriksen GS, Pettersson H (2004) Toxicological evaluation of trichothecenes in animal feed. Anim Feed Sci Technol 114: 205-239

6. Nielsen CCM, Didier A, Dietrich R, Märtlbauer E (2009) Trichothecene-induced cytotoxicity on human cell lines. Mycotoxin Res 25:77-84

7. Thuvander A, Wikman C, Gadhasson I (1999) In vitro exposure of human lymphocytes to trichothecenes: Individual variation in sensitivity and effects of combined exposure on lymphocyte function. Food Chem Toxicol 37:639-648

8. Shewry PR (2009) Wheat. J Exp Bot 60:1537-1553

9. Nightingale MJ, Marchylo BA, Clear RM, Dexter JE, Preston KR (1999) Fusarium head blight: effect of fungal proteases on wheat storage proteins. Cereal Chem 76:150-158

10. Anjum FM, Khan MR, Din A, Saeed M, Pasha I, Arshad MU (2007) Wheat gluten: high molecular weight glutenin subunitsstructure, genetics, and relation to dough elasticity. J Food Sci 72:R56-R63

11. Wieser H (2000) Comparative investigations of gluten proteins from different wheat species I. Qualitative and quantitative composition of gluten protein types. Eur Food Res Technol 211:262-268

12. Wieser H, Antes S, Seilmeier W (1998) Quantitative determination of gluten protein types in wheat flour by reversed-phase high-performance liquid chromatography. Cereal Chem 75: $644-650$

13. Boyacioglu D, Hettiarachchy NS (1995) Changes in some biochemical-components of wheat-grain that was infected with Fusarium-Graminearum. J Cereal Sci 21:57-62

14. Wang JH, Wieser H, Pawelzik E, Weinert J, Keutgen AJ, Wolf GA (2005) Impact of the fungal protease produced by Fusarium culmorum on the protein quality and breadmaking properties of winter wheat. Eur Food Res Technol 220:552-559

15. Eggert K, Wieser H, Pawelzik E (2010) The influence of Fusarium infection and growing location on the quantitative protein composition of (Part I) emmer (Triticum dicoccum). Eur Food Res Technol 230:837-847

16. Pekkarinen AI, Jones BL (2002) Trypsin-like proteinase produced by Fusarium culmorum grown on grain proteins. J Agric Food Chem 50:3849-3855

17. Pekkarinen A, Mannonen L, Jones BL, Niku-Paavola ML (2000) Production of proteases by Fusarium species grown on barley grains and in media containing cereal proteins. J Cereal Sci 31:253-261

18. Phalip V, Delalande F, Carapito C, Goubet F, Hatsch D, LeizeWagner E, Dupree P, Van Dorsselaer A, Jeltsch JM (2005) Diversity of the exoproteome of Fusarium graminearum grown on plant cell wall. Curr Genet 48:366-379 
19. Pekkarinen AI, Longstaff C, Jones BL (2007) Kinetics of the inhibition of Fusarium serine proteinases by barley (Hordeum vulgare L.) inhibitors. J Agric Food Chem 55:2736-2742

20. Brzozowski B, Dawidziuk K, Bednarski W (2008) Gliadin degradation by proteases of Fusarium genus fungi different in vivo and in vitro conditions. Pol J Nat Sci 23:188-206

21. Abonyi T, Kiraly I, Tomoskozi S, Baticz O, Guoth A, Gergely S, Scholz E, Lasztity D, Lasztity R (2007) Synthesis of glutenforming polypeptides. 1. Biosynthesis of gliadins and glutenin subunits. J Agric Food Chem 55:3655-3660

22. Laemmli UK (1970) Cleavage of structural proteins during assambly of head of bacteriophage-T4. Nature 227:680-685

23. Masci S, D’Ovidio R, Lafiandra D, Kasarda DD (1998) Characterization of a low-molecular-weight glutenin subunit gene from bread wheat and the corresponding protein that represents a major subunit of the glutenin polymer. Plant Physiol 118:1147-1158

24. Shewry PR, Halford NG (2002) Cereal seed storage proteins: structures, properties and role in grain utilization. J Exp Bot 53:947-958

25. Wieser H (2001) 25 Jahre Getreideforschung an der DFA 1975-1999. Deutsche Forschungsanstalt für Lebensmittelchemie, Munich

26. Dewar D, Pereira SP, Ciclitira PJ (2004) The pathogenesis of coeliac disease. Int J Biochem Cell Biol 36:17-24

27. Koning F, Schuppan D, Cerf-Bensussan N, Sollid LM (2005) Pathomechanisms in celiac disease. Best Pract Res Clin Gastroenterol 19:373-387 